\title{
DESIGN OF LARGE SPACE CABLE ROOFS WITH RETRACTABLE SYSTEMS TO OPEN AND CLOSE
}

\author{
Prof Kanggeun Park ${ }^{1}$, Prof Mijin Park ${ }^{2} \&$ Prof Sanghwa Shin ${ }^{3}$
}

Abstract- This study is to analyze for the design considerations and structural characteristics on the retractable cable truss roof system that can be opened and closed in accordance with external climatic conditions. Cable truss systems are very lightweight compared to other steel roof systems, and has the advantage of being able to design large space roofs. It is a structural system suitable for the roof system of large space stadium such as football stadium, tennis stadiums, baseball stadiums, viewing facilities, and exhibition facilities. After performing a geometric nonlinear analysis on several $100 \mathrm{~m}$ span retractable cable roof systems, the authors will analyzed the deflection of overall roof, tensile forces of cables, and compressive forces of roof posts from analysis results. The results of this study will be a very useful guideline for the design of retractable large span cable roofs. And it is useful information to control the slope of the roof slope and the sag ratio of the cable truss by adjusting the height of the post from the deformation or deflection of the whole roof.

Keywords - Structural characteristics, Retractable cable truss roof systems, Large span space roofs, Stadium roof systems, Geometric nonlinear analysis

\section{INTRODUCTION}

The cable truss roof systems with retractable systems that can be opened and closed is a system mainly used for large space lightweight roofs such as football stadiums, tennis stadiums, theaters, exhibition halls and the like. The cable truss system has that the upper and lower cables are connected by bracing cables to resist the up and down load of the roof. The cable roof system with the structural concept of a spoke wheel system is consists of outer compression ring, a center hub post, and continuous radial truss cables. The outer circular ring acting compression forces is in equilibrium with the tensile forces of inner radial cables. The upper ridge cables and the lower valley cables with a large prestress are connected to each other by a bracing cable to ensure structural stability and rigidity. The ridge cables and the valley cables are resiliently prestressed and the curvature in the reverse direction cables is maintained the stable shape.

In the cable truss systems, various cables have strong mechanical properties and high tensile strength, enabling the design of large space lightweight roof of 100 300m. Wire rope is a type of cable which consists of several strands of metal wire twisted into a helix. Steel wires for wire ropes are normally made of non-alloy carbon steel with a carbon content of 0.4 to $0.95 \%$. These cables have a very strong tensile forces, but have very flexible and no the bending resistance. The retractable roof system opens and closes the part of roof to maintain the required optimum environment of the stadium to overcome the outside extreme climate, and it is possible to play in cold weather and hot weather, and it creates the good environment conditions of a healthy exercise for athletes. In this study, retractable cable roof systems are performed to analyze the mechanical characteristics for geometrical nonlinear behavior. The roof system is analyzed for the deflection of roof and tensile force of cables. We will review the issues to be considered in the design and structural system of retractable cable roof.

\section{STRUCTURAL CONCEPTS FOR RETRACTABLE CABLE ROOF SYSTEMS}

Historically, the roof system of spatial structures has been trying to construct a longer span and a more lightweight roof. In the 1960s, truss structures and concrete shell systems were developed to construct large space roofs. In the 1980s, the structural systems for spatial structures were developed for space frames, cable structures and membrane structures, recently large space roof systems were realized mainly by using tensegrity and hybrid structural systems. Figure 1 shows the process of historical development of large spatial structures.

\begin{tabular}{|l|c|c|c|c|}
\hline Truss & Concrete Shell & Space Frame/Truss, Cable/Membrane & Tensegrity & Hybrid \\
\hline \hline 1960 & $\bullet^{1970}$ & $\bullet^{1980}$ & & \\
\hline
\end{tabular}

Figure 1. Historical development of large spatial structures

\footnotetext{
${ }^{1}$ Department of Architectural Engineering, I'ST Institute of Technology, Seoul, South Korea

${ }^{2}$ Department of Architectural Engineering, Incheon National University, Incheon, South Korea

${ }^{3}$ Department of Urban Planning \& Real Estate, International University of Korea, Jinju, South Korea
} 


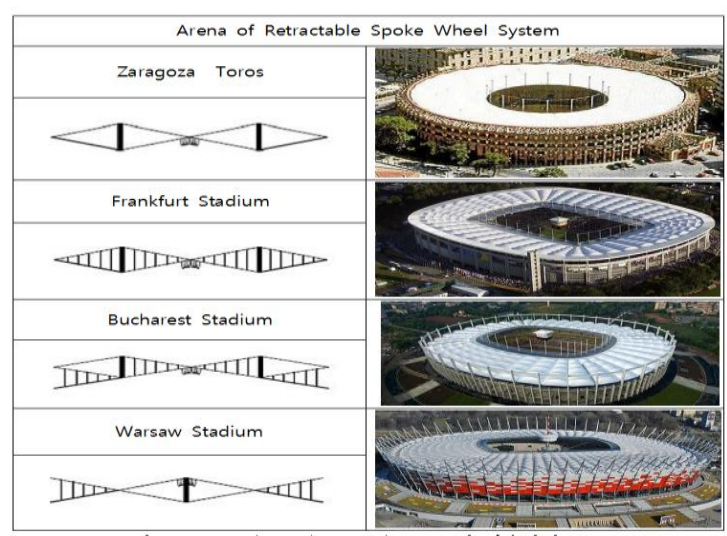

Figure 2. Arena with retractable cable roof systems

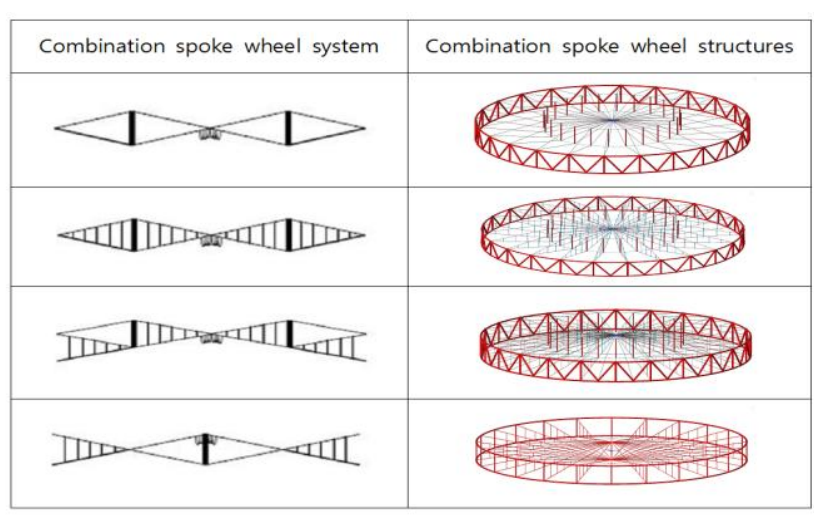

Figure 3. Structural systems of retractable large span cable roofs

Cable truss roofs mainly use a spoke wheel system and a radial roof system to build a lightweight and large span roof as shown in Figure 1 and 2. A large span cable truss spoke wheel roof is a system that combines two spoke wheel systems to adjust the slope of the roof by adjusting the height of the roof post and the outer ring. The outer part of roof is designed a fixed membrane roof, the inner part of roof have the retractable system that can be opened and closed. In the method of opening and closing the entire roof, it is possible to simultaneously open and close the central part and the outside part. In typhoons and heavy snow, it can be closed or opened to prevent damages to the membrane material and structural members. It is better to close the roof during typhoon, and it is better to keep the opening state of roof during snowfall. A retractable roof system is important to consider moving states of retractable roof during opening and closing. Each state changes with load conditions. The safety level depends on the purpose and importance of the building that it is aiming at. The designer should be aware of the desired safety according to the socialism and economics. The method of considering the safety in the opening and closing method is different from the opening and closing state when it moves. The conditions of roof should be clarified taking into consideration whether the roof is to be opened, closed or half-opened. It is normally a good for in a closed state at the time of storm and strong wind in the retractable roof and should be closed when the wind speed exceeds the specified wind speed. Variation of wind speed during roof opening and closing should be considered. The folding-type roofs are designed to the membrane in order to form an appropriate curved surface. The movement method of the opening and closing part can be planned a retractable system for horizontal sliding, horizontal folding or rotational movement. The moveable roof should be considered to structural design for the lateral shaking during the movement, the upward and downward shaking motion when the roof is running.

\section{DESIGN CONSIDERATIONS OF RETRACTABLE CABLE ROOFS WITH OPEN AND CLOSE SYSTEM A. Design concepts of the entire roof-}

Retractable roof systems are as simple as possible, easy to open and close the movable roof and easy to drive. The lightness level of the interior can be changed according to the opening condition of retractable roof, and the influence of the shadow should be considered for the spectator and the player. The opening and closing time of a roof is required to a comprehensive judgment on power consumption and safety issues, the time is a good for 10-20 minutes. Considering the flow of wind in open and closed conditions, natural ventilation and forced ventilation should be considered. A comprehensive evaluation of the effect of sound according to opened and closed conditions should also be made. There is a need for ways to increase lighting effects on interior and exterior lighting problems throughout the design of entire roof. It is recommended that the lighting design of the open state is not different from that of the closed state. The disaster prevention plan should take into consideration the prevention of the initial fire spread, the expansion prevention of the combustion, and the evacuation plan. It should also be predicted that the spread of smoke in the open state is disturbed. A driving room or a management room should be selected in a well-visible position and can be easily prepared for emergencies such as power failure, short circuit, and power out during opening and closing. The important design considerations for retractable roofs are the follows.

a) Opening and closing method: The opening and closing method of a retractable roof should be easy to open and close as possible and a simple driving method. Opening and closing mechanisms that threaten the safety of the entire structure by simple faults should be avoided.

b) Opening and closing time: Appropriate opening and closing time is required and good for usually 10-20 minutes.

c) Ventilation and wind: Natural ventilation or forced ventilation should be designed to prevent internal temperature rise. Consider the flow of blowing air from an opening of the roof.

d) Acoustics: The acoustic level of the room changes depending on the opening or closing state of the roof. When internal noise is leaking to the outside, and the noise influence on the surrounding environment should be considered.

e) Lighting: The lighting height of the large space is important. The higher the height is the less glare lights. The lighting effects of the open and closed states should be designed to be not different. 
f) Disaster prevention and evacuation: Prevention of initial fire spread, prevention of burning spread and evacuation plans should be considered. Diffusion of smoke in the open and closed state and disturbance of smoke due to outside air should also be considered.

g) Maintenance: It is important that the control room for safety management should be located in a well-viewable place, and a management room for monitoring the opening and closing of the roof is important to be installed in a good place.

h) Safety devices and alarm: It is a system that appropriately has a safety device for collision, etc. It should be designed to a headlight and an alarm to prevent the dangerous conditions during the moving of a retractable roof.

i) Opening and closing conditions for a special event: An event is occasions when the roof is open or when it is closed. There is also a case where the retractable roof is adjusted only the position of the upper part of the audience seat.

j) Shadows: Considering the shadows that occur on the playground, the roof plan should be designed to the play of the player, securing the view of the audience, and also securing the view of the camera.

\section{B. Structural design to secure the safety of a retractable roof -}

In the retractable roof structure, the opening conditions of roof are classified with opened, closed and half-open state. The influence of the wind load during opening and closing state is different. The determination to withstand the maximum wind load also depends on the opening and closing method and condition for retractable roof. The wind load which can withstand each open condition is applied to the surface of roof, it is necessary to clearly plan the structural safety within the conditions of no problems in the roof opening management. The snow load in the opened or closed state is determined in consideration of a control management. The snow load to the closed state is the same for the snow load of the general buildings, but when the opening state or closing management fails, an accident can be likely to occur. When the roof is moving, the consideration of wind or seismic load is a particular problem. The probability of strong wind during opening and closing of the roof should be considered.

a) Wind design: The effects of wind load in open, closed, and half-open conditions are different. The tilt up by the difference of roof level and the local concentrated load can be occurred, and the rain does should not flow into the inside of the roof. Deformation or vibration by the wind may occur at the entire roof. The strong wind may cause the rising of the retractable roof and the detachment of the traveling pulley. Wind can cause the retractable panel to rise and the wheel can escape the rail. Cables can occur swinging, pulsation, the failure of end fixation, pretension loss by creep, loosening, and the like. The membrane can cause tearing and ponding by snow and raining water.

b) Snow design: The difference between the behavior of entire roof structure should be analyzed. Creep and eccentric load may occur during long-term snow load. The movement of bulk snow may occur to the impact load and eccentric load. The moving roof becomes difficult to drive due to snow. Ice becomes difficult to move the roof. A roof slope to flow snow should be designed. No local deformations should occur.

c) Earthquake resistance design: The vibration characteristics between the entire roof and that of the panel are different. The pivot axis has a great influence on vibration. It is should be installed a seismometer to have an automatic stop function when an earthquake occurs. There is a possibility that vibration, swinging, collision or sagging by hanging vibration may occur. An earthquake may occur during running of the roof.

\section{GEOMETRICAL NONLINEAR ANALYSIS OF RETRACTABLE LARGE SPAN CABLE ROOFS}

Many structures have a linear behavior, but there are the relationships between force and displacement cannot be described properly with a model of linear behavior. The nonlinearity is due to the nonlinear behavior of the material, the geometric nonlinearity or combined effects. Cables always have a nonlinear behavior that has large displacement. The cable element has been studied of great interest for many years [1-9]. The objective of this study is to analysis the mechanical characteristics on the geometric nonlinear behavior of a radial cable roof system and a spoke wheel roof system for long span retractable cable roofs. The retractable roof is designed as a full control system to overcome extreme outdoor environments such as extreme hot or cold weather, strong wind or sunlight. The cable roof greatly can reduce roof weight compared to other rigid structural system. A retractable cable roof system is a type of structures in which the part of entire roof can be opened and closed. The radial cable roof is an effective structural system for large span retractable roofs, the outer perimeter of the roof is a fixed membrane roof and the middle part is a roof that can be opened and closed. The double arrangement cables of a radial cable truss roof system with reverse curvature works more effectively as a load bearing cables, the cable system can carry vertical load in up and downward direction. To analyze the mechanical characteristics of a retractable cable roof system with central post or roof posts, the authors will investigate the tensile forces of bearing cables, stabilized cables, ring cables, and the deflection of roof according to the height of the post or hub that affects the sag ratio of cable truss.

\section{A. A retractable radial cable roof system-}

The radial cable roof system is composed of the bottoms valley cables to resist the vertical load and the top stable cables to prevent the lifting of the roof, and the cables are installed radially around the roof post. The deformation of roof, the tension of the cables and the compressive force of the roof post are depended on the height of the post and the working load. The radius of the cable roof is $50 \mathrm{~m}$ and the number of radial cables is installed to 40 cable trusses. Since the membrane of the roof is 
installed on the lower cables, the geometric nonlinear analysis is performed by applying the vertical nodal loads on the load bearing cables.
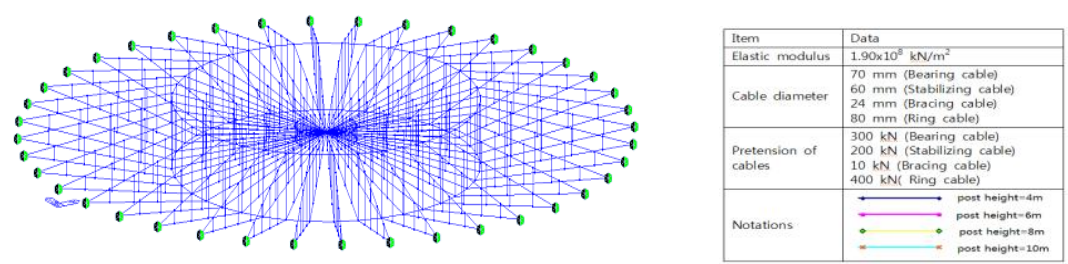

Figure 4. Structural systems of retractable radial cable roof system

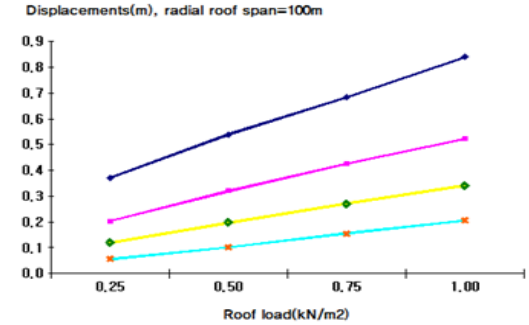

(a) Deflection of roof

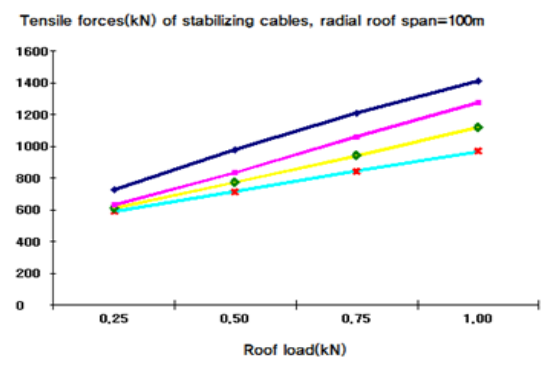

(c) Tensile forces of stablizing cables

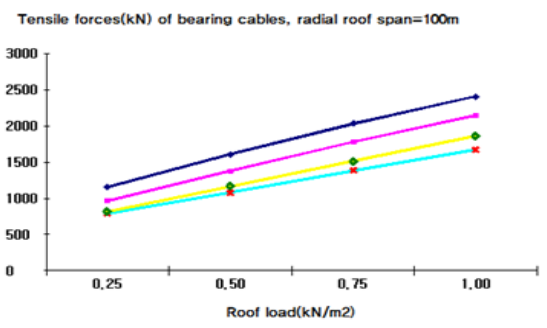

(b) Tensile forces of bearing cables

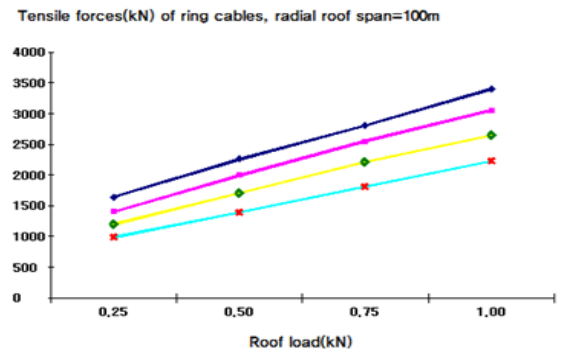

(d) Tensile forces of ring cables

Figure 5. Roof deflection and tensile forces of radial cables

The roof deflection is increased in proportion to the roof load $0.25,0.5,0.75$ and $1.0 \mathrm{kN} / \mathrm{m} 2$, and the roof deflection is decreased as the height of the center post increased. Figure 5 shows the tensile forces of the cables. As the height of the center post increases, the tensile forces of cables are decreased, and the compressive forces are increases in proportion to the post height.

\section{B. A retractable spoke wheel cable roof system-}

The spoke wheel cable roof system is a roof that mimics the system of bicycle wheel. It is structurally more advantages than a general radial cable system and is more simple system which has many structural advantages. Compared to a radial cable roof system, the deformation is small and it is very easy to create the required slope of the retractable roof. Since the cables are connected only at the central hub, the combination of cable members of the roof can be greatly simplified, and the introduction of the pretension of cables is very convenient. No hoop cables are required, and the height of the central hub can be easily to adjust the slope of the roof. The outer ring formed around a cable roof is called a compression ring because compression occurs due to the tensile force of the radial cables. A circular compression ring is connected by end sockets of the radial cable truss. In the geometric nonlinear analysis, the analytical model should be simplified to improve the accuracy and reliability of the analysis results and to reduce the unpredictable repeat incremental analysis times. In order to ignore the influence of the compression ring on the cable system during the geometrical nonlinear analysis, the hinged supports is assumed to set at the connection point of the outer compression ring. The deformation of the spoke wheel roof and the tensile force of the cables are analyzed according to the height of the hub post at the center of entire roof. 

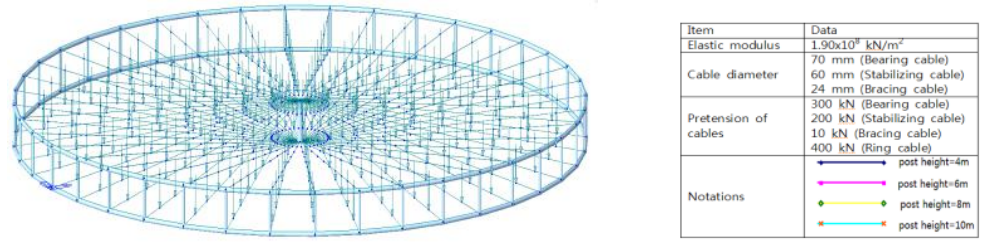

Figure 6. Structural systems of retractable spoke wheel cable roof system

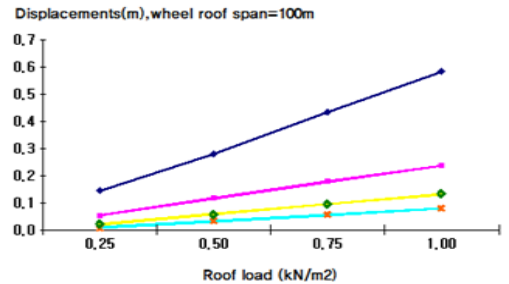

(a) Deflection of roof

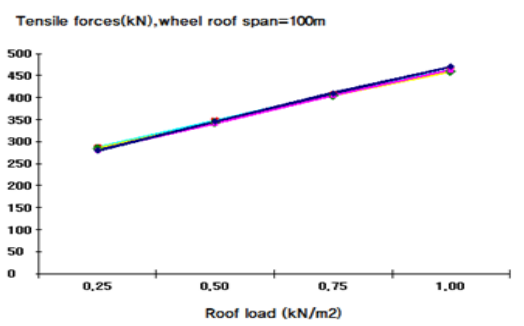

(c) Tensile forces of stablizing cables

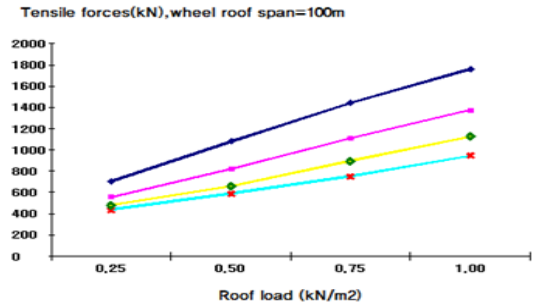

(b) Tensile forces of bearing cables

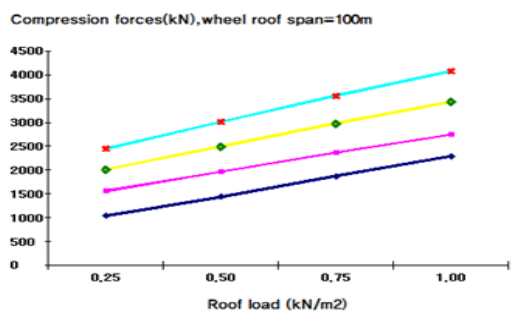

(d) Compression forces of a center post

Figure 7. Roof deflection and tensile forces of cables

In the spoke wheel cable system, since the bearing cables and the stabilized cables are connected to the upper and lower part pf compression rings, the self-balancing forces due to the tensile force of each cable is dispersed. The total tensile forces of cables are self-balancing with the compression ring, so that there is no bending moment, which is structurally important to act gravity direction forces to the lower structures or supports. The X-type cable truss in the reverse direction is connected by a bracing cable, which is a structural system that effectively resists the up and down vertical loads. The hub posts are where the connecting joints of the radial cable are gathered at the center of roof. The roof post has a function to determine the slope of the roof and the sag ratio of the cable, so that a large compressive force acts vertically.

\section{A retractable cable network-membrane system-}

The objective of this study is to estimate the mechanical characteristics and nonlinear behaviors on the geometric nonlinear analysis of curved cable-membrane roof systems for long span lightweight retractable roof structures. The weight of a cablemembrane roof dramatically can reduce, but the single layer cable-membrane roof systems are too flexible and difficult to achieve the required structural stiffness. A curved cable roof system with reverse curvature works more effectively as a load bearing system, the pretension of cables can easily increase the structural stiffness. The curved cable roof system can transmit vertical loads in up and downward direction, and work effectively as a load bearing structure to resists self-weights, snow and wind loads. The nonlinear behavior and mechanical characteristics of a cable roof system has greatly an affect by the sag and pretension. This paper is carried out analyzing and comparing the tensile forces and deflection of curved roof systems by vertical loads. The elements for analysis uses a tension only cable element and a triangular membrane element with 3 degree of freedom in each node. The authors will show that the curved cable-membrane roof system with reverse curvature is a very lightweight roof and small deformation for external loads. And this system is easy to set a retractable membrane which is hanging the cable system of one way direction. 


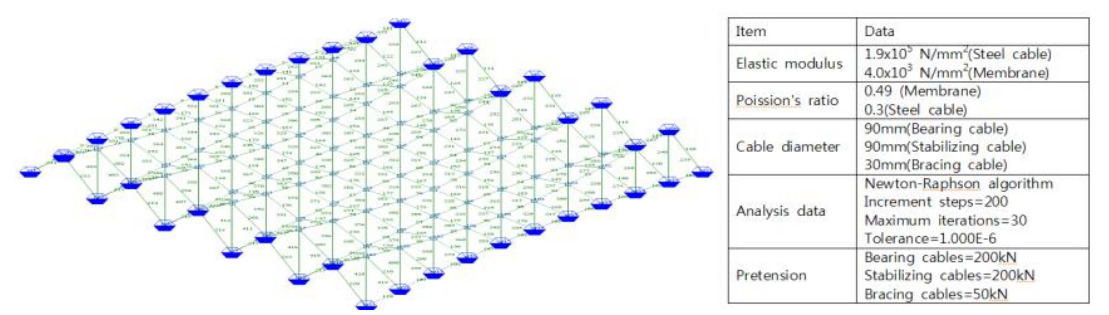

Figure 8. Structural systems of retractable cable network-membrane roof (Rise span ratio=7.5/100=0.075)
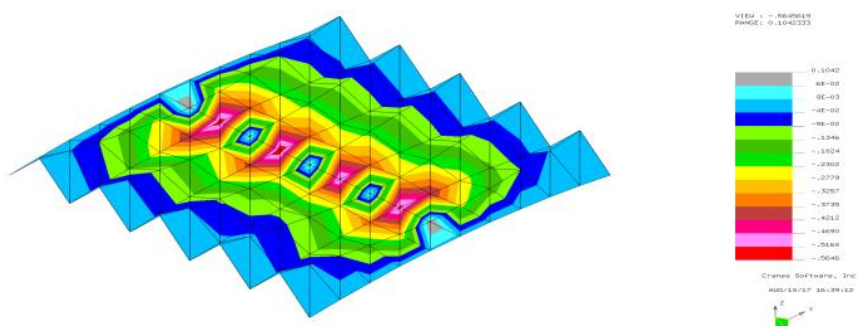

Figure 9. Deflection contour of a rectangular curved roof $\left(0.1042 \sim-0.5646 \mathrm{~m}\right.$, roof load $\left.=0.5 \mathrm{kN} / \mathrm{m}^{2}\right)$
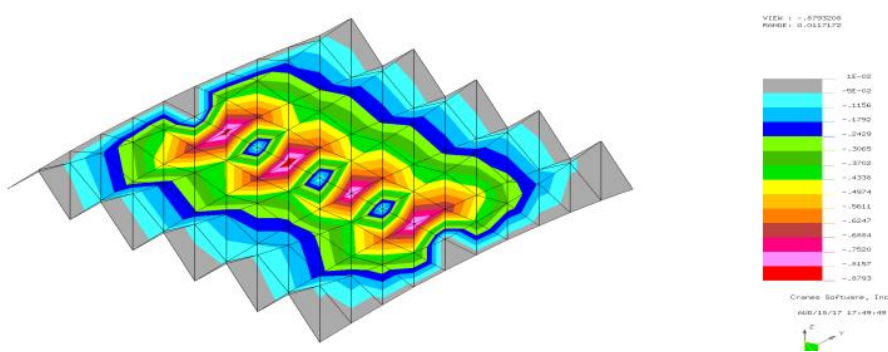

Figure 10. Deflection contour of a rectangular curved roof $\left(0.002 \sim-0.8793 \mathrm{~m}\right.$, roof load $\left.=1.0 \mathrm{kN} / \mathrm{m}^{2}\right)$

\section{CONCLUSION}

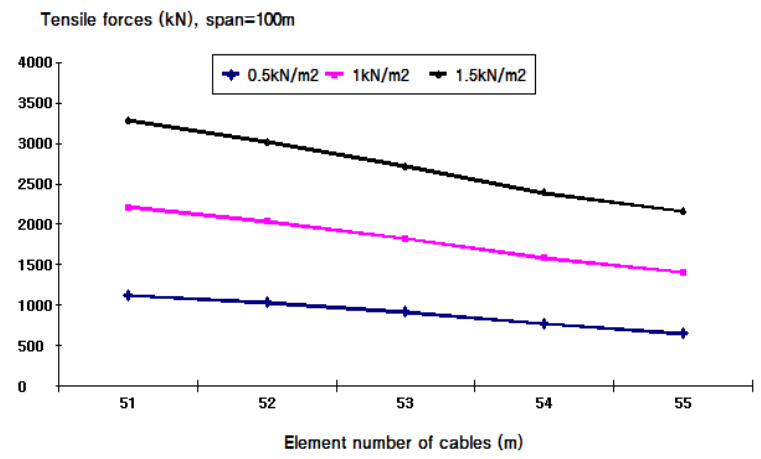

Figure 11. Tensile forces of bearing cables

This research is to analyze for the design considerations and structural characteristics on the retractable cable truss roof system that can be opened and closed in accordance with external climatic conditions.

a) The radial cable roof system is installed in the reverse direction of the bearing cables and the stabilized cables, and the inclination of the roof is controlled by the roof posts. The entire roof of a radial cable roof system is lifted up by the tension of the ring cable connecting each post to form a stable structural system. The spoke wheel roof system is structurally more advantageous than the radial cable roof system because the cable trusses are made of X-shaped trusses and the inclination of the roof is adjusted by the height of central hub, and it is easy to secure the necessary stiffness of cable trusses by initial pretension.

b) The radial cable roof system and the spoke wheel roof system are systems that resist the up and down vertical loads very effectively by the reverse curvature of cable trusses, so it is a system that can effectively resist snow load and wind load.

c) In a result of the geometric nonlinear analysis on the whole roof, the deflection of roof, tensile forces of cables, and compressive force of roof post is increased almost proportionally to roof loads.

d) The spoke wheel roof system occur less overall roof deformation than the radial cable system. The tensile forces are also given to smaller forces, so the diameter of cables can be reduced. 
e) The curved cable-membrane roof system with reverse curvature of each bearing cable is a very lightweight roof and small deformation to resist external loads, and is easy to set a retractable membrane which is hanging the cable system of one way direction

\section{ACKNOWLEDGEMENTS}

a) This research was supported by a grant (17AUDP-B100343-03) from Architecture \& Urban Development Research Program funded by Ministry of Land, Infrastructure and Transport of Korean government.

b) This work was supported by the National Research Foundation of Korea Grant funded by the Korean Government (NRF-2017R1A2B4008120).

\section{REFERENCE}

[1] H.B. Jayaraman, W.C. Knudson, "A curved element for the analysis of cable structures," Computer Structures 14, pp.325-333, 1981

[2] R. Sziliard, "An Energy Balancing Strategy for Solution of Combined Geometric Material Nonlinearity Problems, " Computer \& Structures, 23, 147-162, 1986

[3] Y.H. Kim and S.W. Lee, "A Solid element Formulation for Large deflection Analysis of Composite Shell Structures," Computer \& Structures, 30, 269274, 1988 1. Ayhan Nuhoglu, "Nonlinear analysis of cable systems with point based iterative procedure," Scientific Research and Essays vol 6, pp.11861199,2011

[4] K.G. Park, S.J. Lee, D.W. Lee, "A Study on the Structural System of Flexible Large Span Spatial Roofs Using Steel Cables," Journal of The Residential Environment Institute of Korea, Vol.13(No.4), pp.393-404, 2015

[5] K.G. Park, D.W. Lee, "A Study on the Nature Inspiration Design of Eco-friendly Spatial Buildings," Journal of The Residential Environment Institute of Korea, Vol.14(No.2), pp.1-20, 2016

[6] K.G. Park, M.H. Lee, M.J. Park, "Nonlinear Behaviors of Cable Spoke Wheel Systems," Journal of Korean Association for Spatial Structures, Vol.17(No.1), pp.31-40, 2017

[7] K.G. Park, D.W. Lee, D.I. Choe, "Mechanical Characteristics of Retractable Radial Cable Roof Systems," Journal of Korean Association for Spatial Structures, Vol.17(No.2), pp.21-32, 2017

[8] K.G. Park, D.W. Lee, M.J. Park, "Mechanical Characteristics of Circular Cable Roof Systems," International Journal of Innovations in Engineering and Technology, Vol.8(3), pp.296-302, 2017

[9] K.G. Park, D.W Lee, D.I. Choe, M.J. Park, "Geometric Nonlinear Behaviors of Shallow Shells by Boundary Conditions, " International Journal of Latest Trends in Engineering and Technology, 8(4), 133-139, 2017 